\title{
OFICINA DE ELETRICIDADE: UMA PROPOSTA DE APLICAÇÃO E USO CONSCIENTE DA ENERGIA ELÉTRICA
}

\author{
Thiago de Oliveira Mendes ${ }^{1}$ \\ Cláudio Pires de Mendonça \\ José Maurício de Andrade ${ }^{3}$
}

UFJF

\section{RESUMO:}

A partir de uma reestruturação curricular do ensino médio do Colégio de Aplicação João XXIII - UFJF ocorrida no ano de 2002 tornou-se possível a inserção de espaços alternativos de aprendizagem através de "módulos optativos". Neste cenário curricular surge a proposta do módulo denominado "Oficina de eletricidade", como um espaço de aprofundamento da compreensão do funcionamento de alguns aparelhos através do estudo de alguns circuitos elétricos dos mesmos, visando o uso consciente e seguro da energia elétrica. Considerando o papel formador da escola básica, os espaços de aprendizagem proporcionados pelos "módulos optativos" facultam ao aluno o direito de escolha de temas de seu interesse, buscando identificar aptidões que possibilitem a escolha consciente por cursos de nível superior e também pela profissionalização e a inserção no mercado de trabalho.

Situados num mundo em que novas tecnologias se desenvolvem a todo instante, abrindo novas possibilidades, as práticas realizadas nesse Módulo buscam desmistificar o uso e o trato com a eletricidade tão presente em nossas vidas.

Palavras-chave: Eletricidade - Física experimental - Ensino de Física

\section{ABSTRACT:}

From a curriculum restructuring of High School of the Aplication School João XXIII - UFJF occur-red in 2002, it became possible the insertion of alternative spaces of learning through "optional modules". In this curriculum scenery arises the proposal of a module called "Workshop of Electricity", as a space of deepening learning on working of some appliances through the learning of some electrical circuits targeting the secure and aware use of the electrical energy. Recital the aim the trainer of the basic school, the learning spaces provided by the "optional modules" provide the student the right of choosing about themes of his own interesting, searching to identify suitability that allow the aware choose for graduation courses at universities and also to the professionalization and the insertion on the labour market.

Located on a world where new technologies develop at all time, searching new possibilities, the practices held in this module seek demystify the use of the electricity so on in our lives.

KEY-WORDS: Electricity - Experimental Physics - Physics teaching 
e-Mosaicos - Revista Multidisciplinar de Ensino, Pesquisa, Extensão e Cultura do Instituto de Aplicação Fernando Rodrigues da Silveira (CAp-UERJ) ANO 1 - V. 1 - N. 1 - JUNHO 2012 - ISSN: 2316-9303

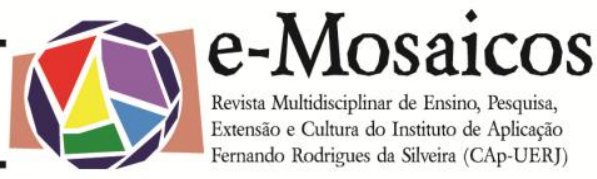

\section{INTRODUÇÃO}

Os avanços tecnológicos ocorridos nas ultimas décadas têm oportunizado ao cidadão um contato maior com aparelhos eletroeletrônicos aumentando assim a demanda para o consumo de energia elétrica. Um dos grandes desafios é o de compreender o funcionamento daqueles aparelhos mais usuais, obtendo deles um melhor rendimento e também se educando para uma forma de consumo de energia elétrica mais eficiente. A partir de uma reestruturação curricular do ensino médio do Colégio de Aplicação João XXIII - UFJF, tornou-se possível a construção de espaços alternativos de aprendizagem, como os módulos optativos na parte diversificada do currículo. Nesse cenário curricular surge então a proposta do módulo "Oficina de eletricidade", como um espaço para a compreensão do funcionamento de alguns aparelhos e circuitos elétricos simples e do uso consciente da energia elétrica.

\section{OBJETIVOS}

A inserção do Módulo "Oficina de eletricidade" tem, como objetivos principais, conscientizar os alunos para o uso racional da energia elétrica, propiciar a compreensão sobre o funcionamento de aparelhos elétricos de um modo geral e montar circuitos elétricos simples. Evidentemente que ao envolver o conhecimento relativo aos princípios e cuidados no uso da eletricidade, temos também como propósito, apurar aptidões para a área em questão. Muitos de nossos alunos identificam-se com a proposta de trabalho e acabam por optar por cursos superiores em áreas afins. Além disso, ao aplicarem o conhecimento adquirido nas práticas desenvolvidas no módulo, os alunos promovem junto a amigos e familiares a divulgação daquilo que aprenderam, ampliando desse modo a inclusão de outras pessoas no processo de conscientização sobre o uso da energia elétrica de modo mais eficiente.

\subsection{PRESSUPOSTOS PARA O DESENVOLVIMENTO DO TRABALHO}

Convencidos de que a saída de um quadro de desmotivação e de fracassos, revelado pelo modelo de ensino inspirado nos anos 80 e diante das perspectivas de mudanças na LDB em 1996, o corpo docente do Colégio de Aplicação João XXIII organizou uma comissão representativa de todas as áreas do conhecimento atuantes naquele estabelecimento, dando inicio a um processo de discussão e construção de uma proposta pedagógica para o ensino médio que atendesse aos anseios de toda a comunidade escolar, inspirados pela nova LDB e motivados pela construção de um novo modelo adequado às novas demandas sociais projetadas para o início do terceiro milênio.

Após um longo processo de discussão, que teve início em 1998 e culminou com a aprovação de um projeto de reforma curricular em 2002, o processo de implantação ocorreu em 2003. O novo currículo é constituído de uma Base Nacional Comum, seriada, e uma parte Diversificada, não seriada, apoiando-se em três princípios fundamentais: integração, flexibilidade e autonomia.

Sendo o currículo anterior essencialmente disciplinar, no qual os componentes curriculares operavam de uma forma praticamente isolada, com um trabalho quase exclusivamente conteudista, sentiu-se a necessidade de uma maior integração entre as disciplinas componentes da base nacional comum, de modo a possibilitar também abordagens interdisciplinares. Houve também 
e-Mosaicos - Revista Multidisciplinar de Ensino, Pesquisa, Extensão e Cultura do Instituto de Aplicação Fernando Rodrigues da Silveira (CAp-UERJ) ANO 1 - V. 1 - N. 1 - JUNHO 2012 - ISSN: 2316-9303

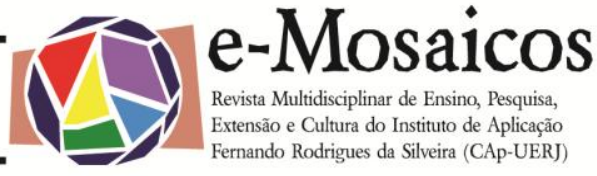

uma demanda pela criação de novos espaços de trabalho, introduzindo-se na parte diversificada do novo currículo os componentes modularizados. Esses Módulos, como foram denominados, se subdividem em dois grupos: os Módulos de desenvolvimento de competências, organizados por áreas de conhecimento, que buscam aprimorar competências básicas nas áreas respectivas, e os Módulos optativos, abrangendo diversas áreas do saber e escolhidos pelos alunos de acordo com seus interesses. É importante ressaltar que a parte diversificada rompe com a seriação, permitindo que alunos de séries distintas frequentem o mesmo módulo. Esse modelo reforça a integração entre os sujeitos da escola, tornando o currículo mais flexível e possibilitando abordagens sobre temas diversos, impraticáveis no modelo anterior, engessado e inchado pelos programas conteudistas impostos pelos vestibulares e outros programas de ingresso em universidades que pouco se dispunham a dialogar com a escola de nível médio.

Por fim, o Colégio de Aplicação João XXIII decidiu investir numa formação autônoma, permitindo que os próprios alunos desempenhassem um papel mais ativo na construção individual de seus currículos, de modo a poderem organizar seus estudos nas áreas em que demonstrarem maior aptidão e interesse.

Nesse contexto, o módulo "Oficina de eletricidade" já esta em sua terceira versão e conta com a participação ativa de estagiários do curso de Licenciatura em Física da UFJF que cursam a disciplina Didática e Prática de Ensino de Física. O módulo é constantemente atualizado a cada ano em que é oferecido aos alunos, aperfeiçoando práticas e processos.

\section{METODOLOGIA}

A aula inicia com uma breve discussão oral sobre o tema abordado, ao qual o professor busca motivar seus alunos, colocando situações do cotidiano envolvendo o tema da aula e questões a serem respondidas por eles no final da prática.

Para as experiências, foram elaborados roteiros a serem seguidos pelos alunos. Estes roteiros contêm advertências sobre os cuidados a serem tomados na manipulação de aparelhos e circuitos elétricos, uma lista com o material utilizado e uma serie de tarefas a serem cumpridas. Ao final da prática o aluno inicia a elaboração de um pequeno relatório que deve ser entregue na semana seguinte.

Estas práticas necessitam de um espaço físico adequado, preferencialmente provido de bancadas, com ferramentas e instrumentos de medida diversos, a fim de reforçar a utilização destes recursos na execução das atividades sugeridas.

Na realização destas atividades práticas os alunos podem se organizar em grupos (caso seja uma atividade individual deve-se verificar os recursos disponíveis, ferramentas, instrumentos, etc) e a todo o momento são monitorados pelo professor.

O público alvo são alunos do ensino médio, independente da série que estejam cursando, uma vez que se rompe com a seriação na parte diversificada do currículo, no que diz respeito aos módulos optativos, possibilitando a integração entre alunos de séries distintas. Há que se destacar que os conteúdos abordados nas práticas não requerem pré-requisitos, pois fazem parte da dinâmica da aula as orientações necessárias para a atividade em questão.

A respeito da avaliação, temos, entre os 
critérios adotados, a freqüência, pois é essencial a participação do aluno em todos os encontros do módulo para que seja possível o alcance de uma habilidade prática individual contínua e um aprofundamento na complexidade das questões abordadas. Para algumas práticas é necessário mais de um encontro para se extrair conclusões do referido tema abordado.

É exigida também a elaboração de relatórios referentes a cada prática realizada. A entrega do relatório é individual, apesar de muitos trabalhos serem realizados em equipes, pois só assim será possível que o professor tire conclusões do aproveitamento de cada aluno. Para o caso de trabalhos em equipe, é observado se ocorre a participação de todos os integrantes do grupo (quando um aluno se demonstra desinteressado pelo tema abordado ele é aguçado por questões feitas pelo professor e, logo se motiva, ao perceber seus companheiros participando da prática).
Ao final do módulo o aluno deverá apresentar, individualmente ou em grupo, um trabalho prático, um experimento ou projeto, elaborado preferencialmente com a utilização de materiais alternativos, na área de eletricidade, com base nos conhecimentos adquiridos no módulo. Será observado o nível de aprofundamento ao discutir conceitos físicos, a interpretação das grandezas físicas envolvidas e a utilização da energia elétrica de forma eficiente (reduzindo desperdícios).

\section{DISCUSSÃO TEÓRICA}

As atividades do módulo foram programadas para a carga horária de uma hora e quarenta minutos semanais, com a duração de três trimestres letivos. É necessário um espaço apropriado para a realização das práticas, as quais estão descritas em forma de síntese na tabela abaixo:

\begin{tabular}{|l|l|}
\hline \multicolumn{1}{|c|}{ Atividades previstas } & \multicolumn{1}{c|}{ Descrição } \\
\hline Introdução à eletricidade. & $\begin{array}{l}\text { Fundamentação para o trato com a eletricida- } \\
\text { de, cuidados e segurança. }\end{array}$ \\
\hline A energia elétrica. & $\begin{array}{l}\text { Geração, transmissão, transformação em ou- } \\
\text { tros tipos de energia, tensão e tipos de cor- } \\
\text { rente elétrica. }\end{array}$ \\
\hline Ferramentas e instrumentos. & $\begin{array}{l}\text { Identificação e utilização correta de ferramen- } \\
\text { tas (tipos de alicate, chaves de fenda e phi- } \\
\text { lips, ferro de solta...), funções de instrumen- } \\
\text { tos de medida diversos, como multímetro, } \\
\text { paquímetro, entre outros. }\end{array}$ \\
\hline Utilização de fontes de alimentação. & $\begin{array}{l}\text { Como operar fontes de alimentação DC, mon- } \\
\text { tagem de um circuito elétrico simples, medi- } \\
\text { das elétricas de tensão e corrente, lei de } \\
\text { Ohm. }\end{array}$ \\
\hline
\end{tabular}




\begin{tabular}{|c|c|}
\hline Resistência elétrica. & $\begin{array}{l}\text { Conhecimento do Código padrão de cores pa- } \\
\text { ra resistores de carvão, verificação experimen- } \\
\text { tal destes valores, montagem de circuitos elé- } \\
\text { tricos simples. }\end{array}$ \\
\hline Multímetro. & $\begin{array}{l}\text { Realização de medidas elétricas com amperí- } \\
\text { metro, voltímetro e ohmímetro, sob diferentes } \\
\text { circuitos elétricos, cuidados para não danificar } \\
\text { o aparelho. }\end{array}$ \\
\hline Software simulador de circuitos. & $\begin{array}{l}\text { Montagem de circuitos mais elaborados atra- } \\
\text { vés simulação computacional, instalações resi- } \\
\text { denciais, utilização de interruptores e fusíveis. }\end{array}$ \\
\hline Montagem de um painel de conexões. & $\begin{array}{l}\text { Um painel para conexões diversas feito de } \\
\text { eucatex perfurado, plugs, pinos, solda... o } \\
\text { painel é utilizado em outras atividades de } \\
\text { montagem de circuitos elétricos. }\end{array}$ \\
\hline Circuitos elétricos & $\begin{array}{l}\text { Montagem de circuitos no painel de conexões, } \\
\text { lâmpadas, resistores, medidas elétricas. }\end{array}$ \\
\hline Instalações elétricas simples. & $\begin{array}{l}\text { Montagem de uma extensão, tomadas ma- } \\
\text { cho/fêmea, utilização de interruptores resi- } \\
\text { denciais para acionar lâmpadas. }\end{array}$ \\
\hline O chuveiro elétrico. & $\begin{array}{l}\text { Compreensão do circuito elétrico de um chu- } \\
\text { veiro, substituição de resistores, controle de } \\
\text { temperatura, potência. }\end{array}$ \\
\hline Circuitos elétricos: serie e paralelo. & $\begin{array}{l}\text { Associação de elementos, lâmpadas e resisto- } \\
\text { res, caracterização de associações, vantagens } \\
\text { e desvantagens na utilização doméstica, me- } \\
\text { didas elétricas. }\end{array}$ \\
\hline $\begin{array}{l}\text { Consumo e economia de energia elé- } \\
\text { trica. }\end{array}$ & $\begin{array}{l}\text { Potência dos aparelhos, consumo diário por } \\
\text { aparelho, interpretação da conta de energia } \\
\text { elétrica, verificação do consumo de energia do } \\
\text { colégio. }\end{array}$ \\
\hline Circuitos elétricos II. & $\begin{array}{l}\text { Montagem de um circuito tree-way com dispo- } \\
\text { sitivos residenciais, as vantagens de uma ins- } \\
\text { talação deste tipo. }\end{array}$ \\
\hline Flash fotográfico. & $\begin{array}{l}\text { Descarga elétrica de um capacitor, caracterís- } \\
\text { ticas de um capacitor, utilização deste elemen- } \\
\text { to, medidas elétricas. }\end{array}$ \\
\hline
\end{tabular}




\begin{tabular}{|l|l|}
\hline Campo magnético. & $\begin{array}{l}\text { Visualização das linhas de campo magnético } \\
\text { com auxilio de imã, limalha de ferro reto } \\
\text { projetor, confecção de uma bússola, pólos } \\
\text { norte/sul magnético e geográfico, campo } \\
\text { magnético e corrente elétrica. }\end{array}$ \\
\hline Motores elétricos. & $\begin{array}{l}\text { Fundamentos sobre o eletromagnetismo, ar- } \\
\text { quitetura de um motor, bobinas, e confecção } \\
\text { de um motor elétrico simples. }\end{array}$ \\
\hline Microcomputador. & $\begin{array}{l}\text { Circuitos elétricos integrados, placas on/off } \\
\text { board, processadores, memória e periféricos. }\end{array}$ \\
\hline $\begin{array}{l}\text { Iluminação pública e termômetro digi- } \\
\text { tal. }\end{array}$ & $\begin{array}{l}\text { Funcionamento de transistores NTC, sensíveis } \\
\text { à temperatura, e LDR, sensíveis a luminosida- } \\
\text { de, utilização, características e aplicações, } \\
\text { montagem um circuito e medidas elétricas. }\end{array}$ \\
\hline Manuais de aparelhos elétricos. & $\begin{array}{l}\text { Informações técnicas, interpretação de tabe- } \\
\text { las, unidades freqüentes, corrente máxima, } \\
\text { condições de uso adequado. }\end{array}$ \\
\hline Energia elétrica e meio ambiente. & $\begin{array}{l}\text { Cuidados com o meio ambiente, a importância } \\
\text { da economia de energia, novas propostas de } \\
\text { obtenção de energia e impactos ambientais, } \\
\text { uso consciente da energia elétrica. }\end{array}$ \\
\hline
\end{tabular}

Abaixo colocamos, a título de exemplificação, escolhido ao acaso, dois roteiros de atividade prática que são entregues a cada aluno do módulo.

UNIVERSIDADE
Fed ERAL D JUIZ DE FORA
Colégio de Aplicação João XXIII
Módulo: Oficina de Eletricidade - Prof. Cláudio Mendonça - Estagiário: Thiago Mendes
Assunto: O Chuveiro Elétrico
Equipe:

1 - Desmontar o chuveiro elétrico (tipo ducha) que está sobre a bancada, observando a ordem de desmontagem, pois a montagem é feita na ordem inversa.

2 - Verificar o aspecto da resistência elétrica encontrada na câmara de aquecimento da água; 
3 - Verificar as posições da chave seletora de potências (Inverno - Verão - Desligado) na qual o chuveiro funciona;

4 - Verificar como a resistência funciona para cada posição (note quando alteramos as posições Inverno - Verão - Desligado, ocorre uma mudança no circuito que é acionado, as diferentes opções de funcionamento do chuveiro seleciona o valor da resistência a ser utilizada), como isso funciona?

5 - Fazer um esquema do circuito do chuveiro, utilizando símbolos padronizados, considerando as três posições indicadas na chave seletora.

6 - Utilizando o multímetro, medir a resistência elétrica do chuveiro em cada uma das posições da chave seletora;

7 - Sabendo que o chuveiro foi fabricado para ser ligado em $120 \mathrm{~V}$, calcular as potências dissipadas nas posições: a) Verão; $\quad$ b) Inverno.

8 - Compare os resultados com os valores nominais indicados pelo fabricante e comente sobre suas conclusões.

9 - Agora que você já esta familiarizado com o chuveiro elétrico, responda: De que forma o chuveiro elétrico é acionado se não há nenhum interruptor para ligá-lo? Não há nenhum circuito elétrico no registro de água do chuveiro, então como o circuito elétrico do chuveiro é ligado e desligado?

10 - Calcular a resistividade elétrica do material de que é feito o resistor do chuveiro, considerando que:

$$
R=\rho \cdot \frac{\ell}{A}
$$

\begin{tabular}{|c|l|}
\hline $\mathrm{R}$ & Resistência elétrica \\
\hline$\rho$ & $\begin{array}{l}\text { Resistividade elétrica do material de que é } \\
\text { feito o resistor }\end{array}$ \\
\hline$\ell$ & Comprimento do condutor \\
\hline $\mathrm{A}$ & Área da secção transversal do condutor \\
\hline
\end{tabular}

11 - Comparar o valor calculado para a resistividade elétrica com a tabela de valores de resistividade elétrica de diversos materiais e indicar de que material é feito o resistor desse chuveiro. 
e-Mosaicos - Revista Multidisciplinar de Ensino, Pesquisa, Extensão e Cultura do Instituto de Aplicação Fernando Rodrigues da Silveira (CAp-UERJ) ANO 1 - V. 1 - N. 1 - JUNHO 2012 - ISSN: 2316-9303

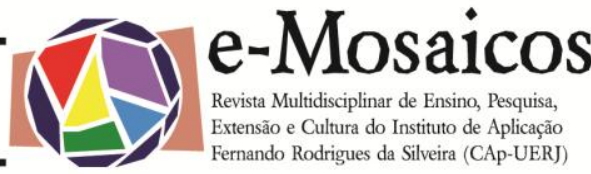

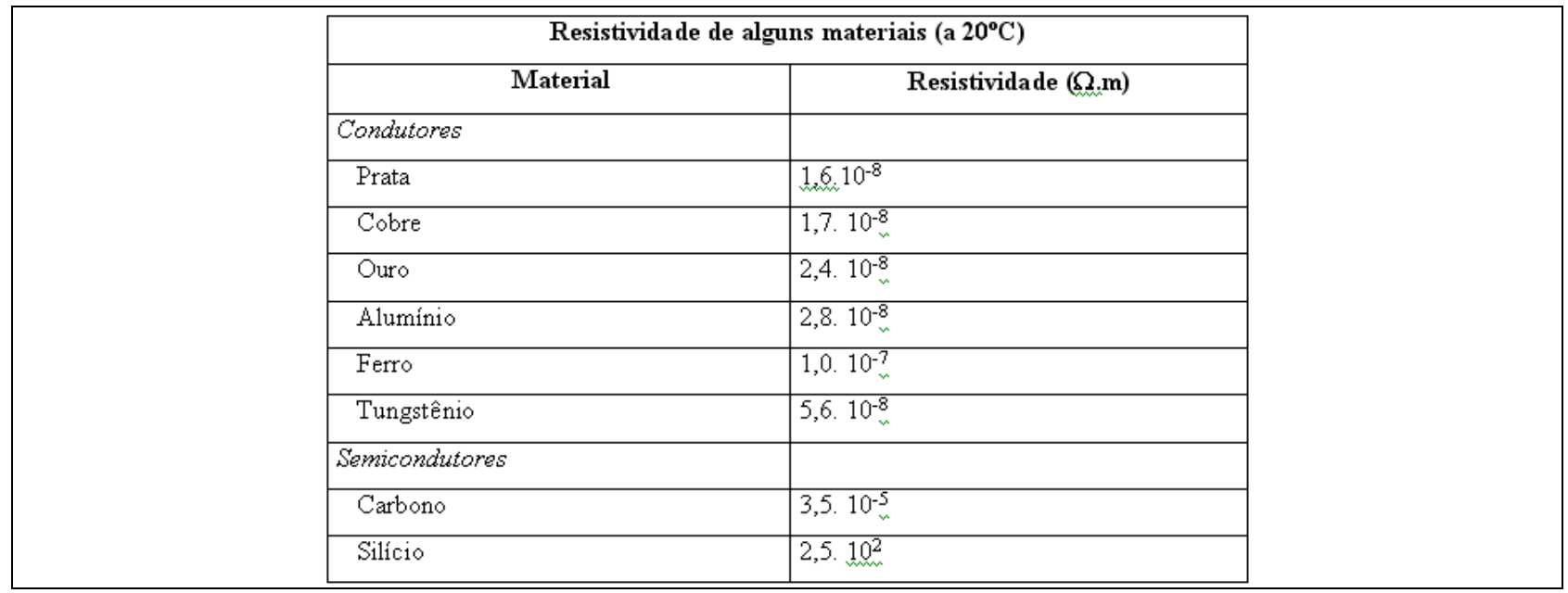

Se você não encontrar o valor na tabela, compare com os tabelados e comente se a resistência do chuveiro pode ser formada por alguma liga metálica, e de quê. Comentar sobre possíveis erros das medidas coletadas.

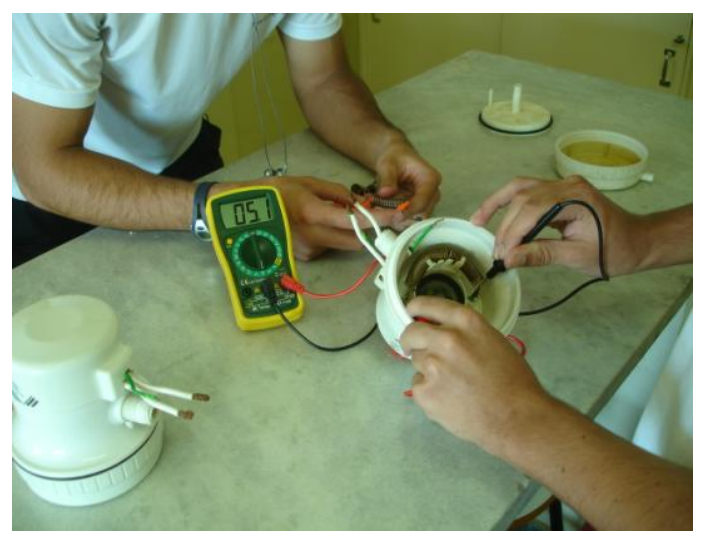

Atividade: "O chuveiro elétrico", alunos verificando o valor da resistência elétrica do resistor de um chuveiro.

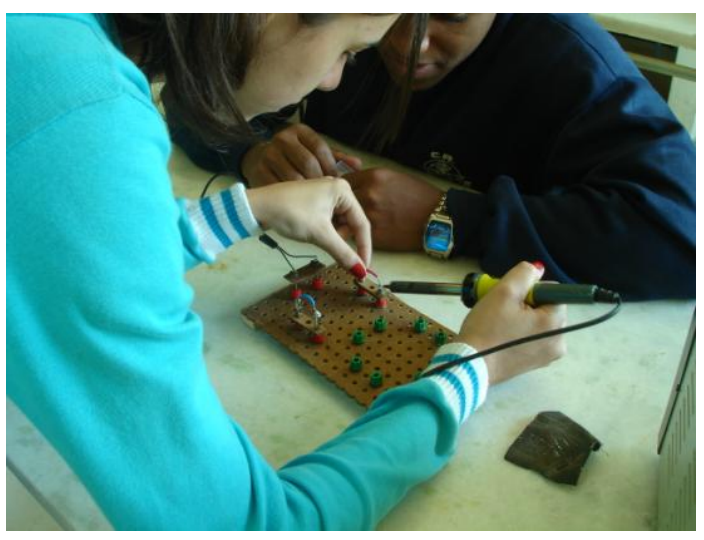

Atividade: "Montagem de um painel de conexões". A aluna realiza um reparo com uso de solda, em conexões no painel de eucatex. 
1- Ao abrir o programa, clique na aba "create a circuit", navegue pelo aplicativo, buscando conhecer suas diversas possibilidades de criação e simulação de circuitos. Clique nos diversos componentes eletrônicos que estão disponíveis na barra de ferramentas para se familiarizar com eles.

2- Na barra de ferramentas, encontram-se os diversos elementos que poderão compor o circuito. Você poderá utilizar num mesmo circuito vários elementos, inclusive elementos iguais. Basta clicar no elemento e arrastá-lo até a área de trabalho. Passando o mouse sobre o elemento, aparecerá o nome desse elemento.

Quando conectado ao circuito, este procedimento indicará, por exemplo, a intensidade da corrente, a tensão elétrica, a potência dissipada etc, no respectivo elemento. Agora vamos trabaIhar, criando alguns circuitos elétricos simples.

\section{MONTE UM CIRCUITO, CONTENDO:}

a) Uma pilha (1,5 V) e uma lâmpada;

b) Acrescente no circuito anterior, um fusível e um interruptor;

c) Duas pilhas em série, um interruptor e duas lâmpadas em série;

d) Refaça o circuito anterior, colocando as duas lâmpadas em paralelo;

e) Uma bateria $(9,0 \mathrm{~V})$, um reostato e uma lâmpada. Procure variar a resistência do reostato e verifique o que acontece com o brilho da lâmpada. Calcule a resistência do reostato para um brilho fraco e para um brilho intenso.

f) Acrescente ao circuito anterior mais duas lâmpadas em paralelo com a primeira, um fusível de entrada e um interruptor. Verifiquem em que condições o fusível "queima"

g) Tente resolver o problema da queima do fusível, acrescentando algum elemento capaz de manter as lâmpadas acesas, com brilho máximo, sem queimar o fusível.

h) Duas baterias $(9,0 \mathrm{~V})$ em série, interruptor, fusível e uma lâmpada em série com outras duas em paralelo. Compare o brilho e a intensidade de corrente nas lâmpadas.

i) Troque as lâmpadas do item anterior por resistores de carbono (código de cores). Verifique o valor das resistências. 
j) Uma bateria, uma sirene e um botão para acionamento.

k) Ao circuito anterior adicione um LED, de modo que ao tocar a sirene, o LED acenda.

I) Duas baterias em paralelo, um fusível e um motor elétrico.

m) Acrescente ao circuito anterior um reostato e verifique o que ocorre na rotação do motor quando variamos a resistência.

\section{DESAFIO}

Existe um tipo de circuito elétrico denominado "Tree way". Ele consiste de uma fonte de tensão, dois interruptores e uma lâmpada. Ele funciona de modo que os dois interruptores, instalados em locais relativamente distantes um do outro, possam ligar e desligar essa lâmpada, independentemente um do outro, porém interligados de tal forma que a lâmpada possa ser ligada por um deles e desligada pelo outro.

Numa casa de dois andares, por exemplo, um dos interruptores poderá estar no pé da escada que liga os andares e o outro no topo da escada. Ao subir a lâmpada que ilumina a escada é ligada no andar de baixo e desligada no andar de cima. Ao descer, liga-se no andar de cima e desliga-se no andar de baixo.

\section{Monte esse circuito.}

Uma vez cumprida a tarefa, não tente fazer isso em sua casa, sem um acompanhamento técnico. Choque, curto-circuito, incêndio... fazem parte dessa realidade. Tome cuidado!

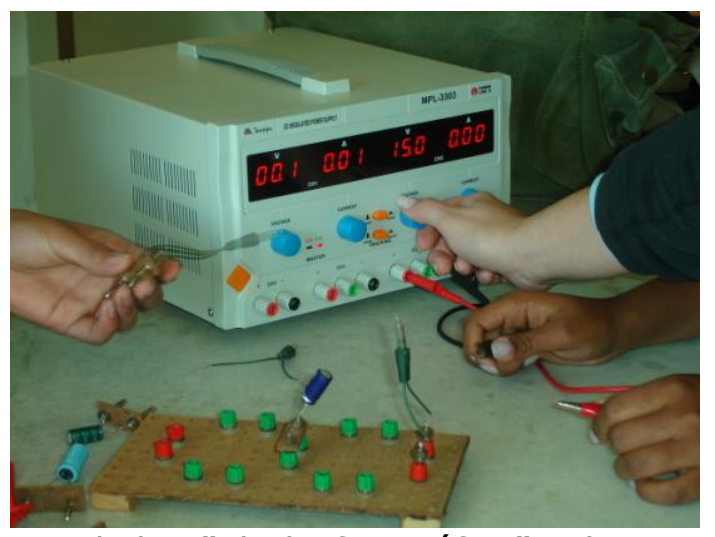

Atividade: "Flash fotográfico", alunos carregando um capacitor para fazer um flash com lâmpada de arvore de natal.

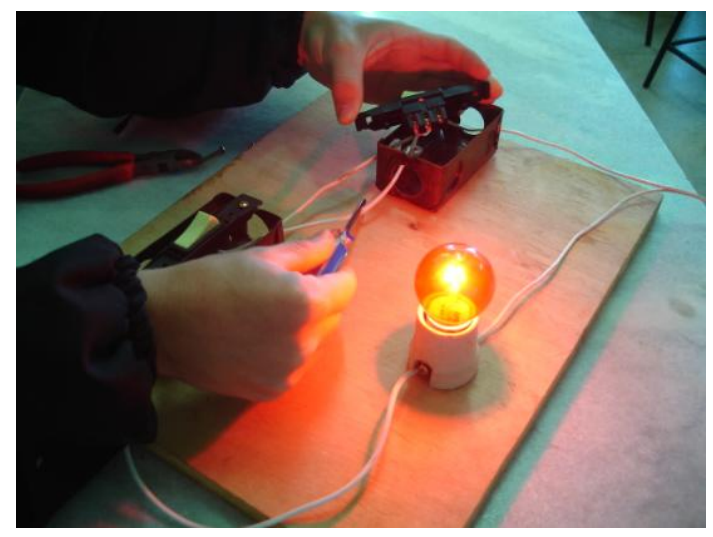

Atividade: "Circuitos elétricos II", alunos verificando conexões na montagem de um circuito tree-way. 
e-Mosaicos - Revista Multidisciplinar de Ensino, Pesquisa, Extensão e Cultura do Instituto de Aplicação Fernando Rodrigues da Silveira (CAp-UERJ) ANO 1 - V. 1 - N. 1 - JUNHO 2012 - ISSN: 2316-9303

Tais atividades e/ou seqüência a serem seguidas podem sofrer alterações no decorrer do módulo, de forma a abordar temas com exemplos atuais e sanar dúvidas de cada aluno, a fim de desmistificar a ciência, sobretudo no trato com a eletricidade.

\section{RESULTADOS}

Os temas abordados proporcionam a utilização correta de ferramentas; o uso de aparelhos elétricos, instrumentos de medida, observando-se a sensibilidade, escala e procedimentos de cuidados e manutenção. As práticas requerem também interpretação das grandezas físicas, a engenharia e arquitetura dos aparelhos elétricos e elaboração de circuitos elétricos simples além de atentar à utilização consciente de energia elétrica, formando assim alunos críticos e capazes de discutir temas diversos relevantes ao assunto eletricidade.

Considerando o papel formador da escola básica, os espaços de aprendizagem proporcionados pelos módulos optativos, facultam ao aluno o direito de escolha de conhecimentos de seu interesse, buscando identificar aptidões que possibilitem a opção por cursos de nível superior e também a profissionalização e inserção no mercado de trabalho.

Um dos grandes desafios que se coloca é o real papel que se deve desempenhar uma escola de nível médio na formação para o mundo do trabalho. Esse papel formador conflita com interesses de grupos atuantes nesse processo, como pais e alguns educadores, de que esse papel só se restringe a preparar os jovens para 0 ingresso em universidades. Desse modo, perde-se a possibilidade de desenvolver autonomia, maior integração com conhecimentos e profissionais cujo objetivo de estudo vai muito além dos programas propostos para ingresso em universidades.

Situados num mundo em que novas tecnologias se desenvolvem a todo instante, abrindo novas possibilidades, o módulo "Oficina de eletricidade" busca desmistificar 0 uso e o trato com a eletricidade tão presente em nossas vidas.

\section{REFERÊNCIAS BLIBLIOGRÁFICAS}

VASCONCELOS, Marco Antônio Sanford, de; SCHAEFER, Hamilton N R. Laboratório de Eletricidade e Magnetismo - Florianópolis: UFSC, 1983.

RAMOS, Luiz Antonio Macedo; BLANCO, Rosa Leamar Dias; ZARO, Milton Antonio. Eletricidade, Magnetismo e Eletromagnetismo - Porto Alegre: Mercado Aberto Ltda.

LUZ, Antônio Máximo Ribeiro da; Álvares, Beatriz Alvarenga. Física: Volume 3 - São Paulo: Scipione, 2000.

GASPAR, Alberto. Física Eletromagnetismo e Física Moderna: Volume 3 - São Paulo: Ática, 2000.

\footnotetext{
1 tmendes@fisica.ufjf.br - Mestre em Física e Especialização em Educação Matemática. Tem interesse nas áreas de Ensino de Física e Física Experimental. Possui experiência com Educação de Jovens e Adultos (CAp-UFJF), Pré-vestibular Social (CECIERJ-CEDERJ) e Licenciatura em Física à Distância (UAB-UFJF).

2 claudio.mendonca@ufjf.edu.br - Graduado em Física pela Universidade Federal de Juiz de Fora, Especialização em ensino de Física pela mesma instituição e Mestrado em Educação pela Universidade Estadual de São Paulo, com ênfase na formação de professores. Atualmente é professor de Física no Colégio de Aplicação João XXIII da UFJF, atuando também junto ao Centro de
} 
Ciências/Universidade Federal de Juiz de Fora em cursos de capacitação e aperfeiçoamento de professores em Minas Gerais.

3 jmauricio.andrade@ufjf.edu.br - Licenciado em Física pela Universidade Federal de Juiz de Fora (1979), Especialização em Curso para Especialistas e Docentes pela Universidade Federal de Minas Gerais (1985), Especialização em Física pela Universidade Federal de Juiz de Fora (1984) e Mestrado em Educação pela Universidade Estadual de Campinas (1995). Atualmente é Professor Adjunto IV da Universidade Federal de Juiz de Fora. Tem experiência na área de Educação, com ênfase em Ensino-Aprendizagem. 